\title{
Getting it right: the impact of a continuing medical education program on hepatitis $B$ knowledge of Australian primary care providers
}

This article was published in the following Dove Press journal:

International Journal of General Medicine

8 March 2013

Number of times this article has been viewed

\section{Monica Robotin 1,2 \\ Yumi Patton ${ }^{3}$ \\ Jacob George ${ }^{1,4}$}

'School of Medicine, University of Sydney, Sydney, Australia; ${ }^{2}$ Cancer Council New South Wales, Sydney, Australia; ${ }^{3}$ Faculty of Engineering, University of New South Wales, Sydney, Australia; ${ }^{4}$ Storr Liver Unit, Westmead Millennium Institute, Westmead Hospital, Sydney, Australia
Introduction: In Australia, chronic hepatitis B (CHB) disproportionately affects migrants born in hepatitis B endemic countries, but its detection and management in high risk populations remains suboptimal. We piloted a primary care based program for CHB detection and management in an area of high disease prevalence in Sydney, Australia. Prior to its launch, all local general practitioners were invited to take part in a continuing medical education (CME) program on hepatitis B diagnosis and management.

Material and methods: Preceding each CME activity, participants completed an anonymous survey recording demographic data and hepatitis B knowledge, confidence in CHB management, and preferred CME modalities. We compared knowledge scores of first-time and repeat attendees.

Results: Most participants (75\%) were males, spoke more than one language with their patients (91\%), self-identified as Asian-Australians (91\%), and had graduated over 20 years previously (69\%). The majority (97\%) knew what patient groups require CHB and hepatocellular cancer screening, but fewer (42\%-75\%) answered hepatitis B management and vaccination questions correctly. Knowledge scores were not significantly improved by seminar attendance and the provision of hepatitis B resources. At baseline, participants were fairly confident about their ability to screen for CHB, provide vaccinations, and manage CHB. This did not change with repeat attendances, and did not correlate with survey outcomes. Large group CMEs were the preferred learning modality.

Discussion: Knowledge gaps in hepatitis B diagnosis and management translate into missed opportunities to screen for $\mathrm{CHB}$, to vaccinate those susceptible, and to prevent disease complications. The results suggest that a range of innovative $\mathrm{CME}$ programs are required to update general practitioners on the modern management of $\mathrm{CHB}$ infection.

Keywords: hepatocellular cancer, vaccination, screening, continuing medical education, hepatitis B screening, vaccination

\section{Introduction}

Over 350 million people in the world have chronic hepatitis B infection (CHB), ${ }^{1,2}$ and $25 \%-40 \%$ are likely to die from disease complications, such as liver failure and hepatocellular cancer (HCC). ${ }^{3}$ Early diagnosis linked to effective medical support represents the best opportunity to limit disease transmission and prevent complications; this requires improved disease awareness and knowledge among affected populations, as well as their medical care providers. ${ }^{4,5}$ As hepatitis B virus (HBV) infection is endemic in many South-East Asian countries, the Pacific Islands, and some African countries, ${ }^{2-6}$ medical practitioners need to be aware of specific population groups that may benefit from CHB screening, particularly in the context of
Correspondence: Monica Robotin Cancer Council NSW, 153 Dowling St, Woolloomooloo, Sydney, Australia Tel +6I 293341900

Email monicar@nswcc.org.au or 
increased population migration and movement over the last few decades. Due to its long asymptomatic phase, CHB may remain undetected for decades and therefore its initial diagnosis and assessment relies heavily upon the primary care practitioners' clinical acumen and appropriate screening of at-risk patients. ${ }^{7}$

In 2008, the US Centers for Disease Control and Prevention published new guidelines for the public health evaluation and management of people with $\mathrm{CHB}$, recommending hepatitis B testing for all persons born in geographic regions where hepatitis surface antigen (HBsAg) prevalence exceeds $2 \%$, as well as for men who have sex with men and injecting drug users. ${ }^{8,9}$ Similar recommendations have been published for Australia and New Zealand by the local Digestive Health Foundation. ${ }^{10}$ As low disease awareness and a limited understanding of the public health impact of $\mathrm{CHB}$ remain prevalent among health care providers, policymakers, and the general public, the US Institute of Medicine emphasized the critical role played by education and awareness-raising in improving the prevention, detection, and management of viral hepatitis and HCC. ${ }^{11}$

It was estimated that in 2008 some 187,000 Australians were living with $\mathrm{CHB}$ and that this figure would increase to 276,000 by 2017 , leading to a three-fold increase in the incidence of hepatitis B-related HCC. ${ }^{12}$ In the state of New South Wales, $25 \%$ of the population is born overseas and HCC incidence rates are highest in Southwest Sydney, where approximately 6000 residents born in Vietnam or China are estimated to have $\mathrm{CHB},{ }^{13}$ yet many remain unaware of their status and are therefore unable to access appropriate care. ${ }^{14}$ To reduce the burden of hepatitis B-related liver disease in this population, the Cancer Council of New South Wales developed the B Positive program, which seeks to support local general practitioners (GPs) in southwest Sydney to identify and manage their patients with CHB. ${ }^{15}$

As previous research suggested that primary care professionals have unmet educational needs with regards to hepatitis $B,^{7,16-19}$ we invited all GPs in the program area to take part in a continuing medical education (CME) program designed to enhance their clinical competence in diagnosing and managing hepatitis B infection.

Prior to the program's launch, we sought to ascertain local GPs' baseline hepatitis B knowledge and practices, and to measure the impact of the educational program on practitioners' knowledge, self efficacy, and their preferences regarding CME activities.

\section{Material and methods Program design}

The CME program was designed in collaboration with academic GPs and hospital clinicians, and was approved by the Education Committee of the Royal Australasian College of General Practitioners (RACGP) and the Sydney South West Area Health Service Ethics Review Committee. Topics included in the CME program were the prevalence and epidemiology of hepatitis B, hepatitis B testing and blood test interpretation, the natural history of CHB infection, and the clinical assessment and management of patients with HBV infection.

The educational program was integrated into an active learning module consisting of three learning activities. The successful completion of all learning activities led to the awarding of 40 RACGP points counting towards the GPs Quality Improvement and Continuing Professional Development Program (Australian GPs need to accrue 130 RACGP points each triennium).

\section{Program delivery}

Each learning activity consisted of a predisposing activity (including prereading and a brief questionnaire), a faceto-face seminar (comprising a mixture of interactive and didactic activities), and a postseminar activity (encouraging participants to reflect on the skills and knowledge needed to manage $\mathrm{CHB}$ and associated liver diseases). The sessions were delivered by academic hepatologists and gastroenterologists, and were facilitated by an academic GP and B Positive program staff, and combined lectures with case studies and small group work (involved in identifying barriers to testing and referral, or developing a chronic disease management plan).

Prereadings consisted of short chapters of a hepatitis B monograph especially commissioned for GPs, titled "B Positive: all you wanted to know about hepatitis B," provided to all GPs registering for the CME program..$^{20}$ The seminars discussed the epidemiology of hepatitis B infection, hepatitis B testing, the management of CHB and its complications, and HCC screening. Each seminar consisted of one or more lectures addressing these topics, complemented by case studies and/or group work.

\section{Program evaluation}

Participants were invited to complete a satisfaction survey that sought feedback on the extent to which the CME activities met designated learning objectives, the quality of the 
educational component, relevance to GP practice, and the degree to which they offered opportunities for interaction with other participants.

At the commencement of each hepatitis B seminar we invited all participants to complete a hepatitis B knowledge survey and to rate how confident they felt about managing patients with CHB. The same survey was administered prior to each seminar and respondents were asked to indicate the number of seminars previously attended.

We also collected participants' demographic information (ethnicity, gender, number of years since graduation), practice characteristics (solo or group practice, part-time versus full-time work, and whether they used additional languages during patient consultation) and elicited their preferences regarding CME activities.

The hepatitis B knowledge survey was originally developed and validated by the Department of Medicine, University of California San Francisco, ${ }^{17}$ and was adapted to Australian conditions with the authors' permission.

\section{Outcome measures}

Main outcome measures were the knowledge of populations requiring: (1) screening for $\mathrm{CHB}$, (2) hepatitis B vaccination, and (3) hepatitis B blood test interpretation. Secondary outcome measures included self-reported levels of hepatitis B knowledge and the respondents' preferred learning format. Results were reported separately for first-time attendees (as baseline knowledge scores) and for participants who attended more than one educational seminar (repeat attendees). Other outcomes related to self-efficacy in managing $\mathrm{CHB}$ and preferred educational formats were also recorded.

\section{Statistical analysis}

We examined the frequencies of correct responses to the 23 knowledge questions and calculated a summary score by adding the total correct answers (minimum score $=0$, maximum $=23$ ). We evaluated bivariate associations between knowledge scores, sociodemographic characteristics, and provider screening using chi-square tests for comparisons of categorical variables. We compared knowledge scores between first-time attendees and those who attended more than one educational session. Interest in further education and preferred formats was compared by participant and practice characteristics. Participant confidence in dealing with hepatitis B-related clinical problems was ascertained using a Likert five-point scale. Survey results were analyzed using SAS version 9.2 software (SAS Inc, Cary, NC, USA).

\section{Results}

Four seminars were offered over a period of 12 months, and a total of 130 surveys were completed, of which 69 (53\%) were filled in by first-time attendees, and the remaining 61 (47\%) by GPs who attended more than one seminar. Response rates to the preseminar surveys ranged from $96 \%$ to $100 \%$ and the number of seminar participants ranged from 23 to 44 . Of GPs attending $>1$ seminar, 31 (or 51\%) attended two seminars, 18 (29\%) attended three, and 12 (20\%) attended four seminars.

The majority of participants (75\%) were male and 91\% spoke at least one additional language (apart from English) with their patients. Ninety one percent self-identified as Asian-Australians and 54\% worked full-time. The most common ethnicity was Chinese (42\%), followed by Vietnamese (22\%), and other Asian (22\%), which included Indian, Thai, Laotian, Sri Lankan, Malaysian, and Burmese. Most (69\%) had graduated from medical school more than 20 years previously, and the majority (53\%) cared for fewer than 20 patients with CHB. The demographic characteristics of participating GPs are summarized in Table 1.

\section{Baseline hepatitis B survey}

The mean overall knowledge score at baseline (prior to attending any hepatitis B seminars) was 14.7/23 (range 7-20), or $64 \%$ correct answers. While $42 \%$ of respondents answered that the correct test to diagnose $\mathrm{CHB}$ is $\mathrm{HBsAg}$, $48 \%$ chose a combination of tests which included HBsAg testing and $10 \%$ chose answers which did not include HBsAg. Threequarters of respondents (75\%) correctly identified $\mathrm{HBsAb}$ (or anti-HBs) as the correct test for ascertaining hepatitis B immunity.

The majority of participants knew that CHB prevalence was higher in Chinese born migrants compared to

Table I Sociodemographic characteristics of the 69 general practitioners attending the CME program

\begin{tabular}{ll}
\hline Characteristic & Number (\%) \\
\hline Male gender & $5 I(75)$ \\
Asian Australians & $62(91)$ \\
Career stage & $62(91)$ \\
$\quad \%$ early/mid/late career & $(6 / 24 / 69)$ \\
Speaking $\geq$ I language with patients & $62(91)$ \\
Working full-time & $37(54)$ \\
Caring for $\geq 20$ patients with CHB & $32(47)$ \\
\hline
\end{tabular}

Notes: Early career: graduated from medical school in the last 10 years; mid-career: I I-20 years since graduation; late career: $>20$ years since graduation.

Abbreviations: $\mathrm{CME}$, continuing medical education; $\mathrm{CHB}$, chronic hepatitis $\mathrm{B}$. 
Australian-born individuals (90\%) and Australian-born Chinese (92\%), but fewer (60\%) participants knew that CHB prevalence in Chinese born migrants was higher than among people with human immunodeficiency virus infection, men who have sex with men, or injecting drug users. Only $16 \%$ knew the answer to the question regarding the prevalence of $\mathrm{CHB}$ in Chinese born migrants.

Over $90 \%$ correctly identified groups needing HBV vaccination (Table 2), but more than half also recommended vaccinating other low-risk groups. Only a small proportion of respondents $(21 \%)$ were aware of how to complete an interrupted HBV vaccination schedule. The majority of participants knew CHB can be controlled by medication (72\%) and agreed that persons with $\mathrm{CHB}$ should be screened for liver cancer (97\%), but 38\% believed that CHB is curable.

The mean knowledge score $(63 \%)$ did not vary by career stage, pattern of work (part-time: $57 \%$, full-time: $64 \%, P$-value $=0.36)$, or number of $\mathrm{CHB}$ patients cared for ( $<20$ patients with CHB: $65 \%$; $\geq 20$ patients: $62 \%$, $P$-value $=0.65)$.

\section{Survey results in repeat attendees}

Repeat attendees completed the same knowledge questionnaire every time prior to attending a hepatitis B seminar. There was no significant difference in the demographic characteristics of GPs who attended one versus multiple CME sessions. The mean score of returning attendees was

Table 2 Knowledge regarding hepatitis B among GPs participating in a B Positive education session

\begin{tabular}{|c|c|c|c|}
\hline Topic & $\begin{array}{l}\% \text { correct answer } \\
\text { first time attendees }\end{array}$ & $\begin{array}{l}\% \text { correct answer } \\
\text { returning attendees }\end{array}$ & $P$-value \\
\hline \multicolumn{4}{|l|}{ Interpretation of HBV tests } \\
\hline What test to order to screen for $\mathrm{CHB}$ & 42.4 & 40.3 & 0.81 \\
\hline What tests to order to confirm immunity against HBV & 75.4 & 79.0 & 0.62 \\
\hline \multicolumn{4}{|l|}{ HBV epidemiology } \\
\hline Overall prevalence of $\mathrm{CHB}$ in Chinese migrants & 15.9 & 11.7 & 0.50 \\
\hline $\mathrm{CHB}$ prevalence in Chinese-born migrants versus & 91.4 & 91.7 & 0.96 \\
\hline \multicolumn{4}{|l|}{ Australian-born Caucasians } \\
\hline $\mathrm{CHB}$ prevalence in Chinese-born migrants versus & 93.1 & 91.7 & 0.77 \\
\hline \multicolumn{4}{|l|}{ Australian-born Chinese } \\
\hline $\mathrm{CHB}$ prevalence in Chinese-born migrants versus & 60.3 & 72.6 & 0.16 \\
\hline \multicolumn{4}{|l|}{ Australians with HIV infection } \\
\hline $\begin{array}{l}\mathrm{CHB} \text { prevalence in Chinese-born migrants versus } \\
\text { men who have sex with men }\end{array}$ & 58.6 & 75.0 & 0.06 \\
\hline \multicolumn{3}{|l|}{ injecting drug users } & $<0.01$ \\
\hline \multicolumn{4}{|l|}{ CHB statements } \\
\hline $\mathrm{CHB}$ can be controlled by medication & 71.9 & 73.8 & 0.81 \\
\hline $\mathrm{CHB}$ is not curable & 61.5 & 70.5 & 0.29 \\
\hline $\mathrm{CHB}$ patients need $\mathrm{HCC}$ screening & 96.9 & 98.4 & 0.60 \\
\hline \multicolumn{4}{|l|}{ Population groups needing screening for $\mathrm{CHB}$} \\
\hline 35-year-old Chinese-born migrant & 95.2 & 98.4 & 0.32 \\
\hline Receptionist of a primary care clinic & 43.5 & 44.3 & 0.94 \\
\hline 35-year-old Caucasian, no family history of hepatitis B & 84.4 & 90.0 & 0.35 \\
\hline 40-year-old Chinese person, no family history of hepatitis B & 59.4 & 61.7 & 0.79 \\
\hline Person with HIV infection & 100.0 & 100.0 & \\
\hline 35-year old person who had blood transfusion in childhood & 92.3 & 96.7 & 0.28 \\
\hline \multicolumn{4}{|l|}{ Vaccination schedule } \\
\hline \multicolumn{4}{|l|}{ first $H B V$ vaccine 2 years beforehand } \\
\hline \multicolumn{4}{|l|}{ Population groups needing HBV vaccination } \\
\hline Person recently diagnosed with STI & 92.2 & 95.1 & 0.51 \\
\hline Substance abuse counselors & 17.5 & 26.2 & 0.24 \\
\hline Person with HIV infection & 96.9 & 96.7 & 0.95 \\
\hline Person with multiple sex partners & 95.3 & 96.7 & 0.69 \\
\hline Food handlers & 40.3 & 65.6 & $<0.01$ \\
\hline
\end{tabular}

Abbreviations: GP, general practitioner; HBV, hepatitis B virus; CHB, chronic hepatitis B; HCC, hepatocellular cancer; HIV, human immunodeficiency virus; STI, sexually transmitted infection. 
15/23 (range 9-21), which was not statistically different from the score for first-time attendees (14.7). However more respondents knew CHB prevalence rates were higher in Chinese-born migrants compared to injecting drug users $(P<0.001)$, and that hepatitis $\mathrm{B}$ vaccination is not recommended for food handlers $(P<0.01$; Table 2$)$.

\section{Self-reported level of knowledge regarding $\mathrm{CHB}$ and preferred learning modalities}

Before attending any hepatitis B seminars, most participants were fairly confident about their ability to identify patients in need of CHB screening or a specialist referral; on a Likert scale of 1 (low) to 5 (high), participants rated their confidence at 3.9 for both questions. They were also fairly confident about their ability to manage $\mathrm{CHB}$ as a notifiable disease (mean score 3.8) and to ascertain who requires HBV vaccination (mean score 4.0). Self-reported levels of knowledge increased slightly following repeat attendance, but this was not statistically significant (Table 3).

Preferred learning modalities were large group CME (67\%), small group discussions among peers (49\%), internetbased interactive learning $(36 \%)$, mailed resources $(35 \%)$, and small group learning delivered at the practice level (28\%). Preferred learning modalities did not change between first-time and repeat attendees.

\section{Discussion}

Most GPs attending a CME program on hepatitis B in an area of Sydney with a high burden of hepatitis B had many years of practice experience, spoke another language in addition to English with their patients, and were fairly confident in their ability to manage hepatitis B. However, a hepatitis B knowledge survey identified knowledge gaps regarding patient groups needing HBV testing, HBV vaccination, and what represents optimal CHB management. As knowledge scores were not significantly improved by seminar attendance and the provision of hepatitis B resources, the CME activity did not adequately meet GPs' information and education needs on hepatitis B diagnosis and management.

Using the same survey instrument as two previously published US surveys allowed us to compare the hepatitis B knowledge of primary care providers in the US and Australia: ${ }^{16,17}$ the test used to diagnose $\mathrm{CHB}$ was correctly identified by just $37 \%$ of surveyed primary care physicians in San Francisco, ${ }^{17} 45 \%$ of attendees of a university-based CME primary care conference, ${ }^{16}$ and $42 \%$ of Australian attendees. As HBsAg is commonly ordered in combination with other blood tests, it could be argued that all answers which included HBsAg should be considered correct. If so, the proportion of correct answers increased to $70 \%$ in the San Francisco survey, ${ }^{17}$ and $90 \%$ in the Australian survey. ${ }^{16}$ However knowledge scores may not readily capture the working knowledge of participants, as illustrated by a Canadian study of family medicine trainees: while only about half (49\%) of respondents answered correctly questions relating to hepatitis B screening tests, a much higher proportion (86\%-91\%) correctly interpreted serological test results when presented as part of a clinical scenario. ${ }^{21}$

A recent Australian survey seeking to estimate the proportion of people with $\mathrm{CHB}$ receiving antiviral treatment in high CHB prevalence areas found that southwest Sydney (the target area for the B Positive project) has the highest proportion of patients receiving $\mathrm{CHB}$ treatment, compared to other high CHB prevalence areas in Australia. ${ }^{22}$ While there may be alternative explanations for these encouraging statistics, it could be surmised that the CME program has positively impacted the ability of local GPs to appropriately screen and refer patients with $\mathrm{CHB}$ in their practices.

Awareness of CHB prevalence in different populations, the ability to correctly interpret blood test results, and the ability to recommend vaccinations for at-risk individuals are cornerstones of modern CHB management. The discrepancy between the respondents' opinion of their knowledge of CHB and what transpired through objective measurement of this knowledge is concerning, particularly as we cannot rule out selection bias for GPs attending the seminars

Table 3 GP confidence in dealing with HBV clinical problems in first-time versus repeat attendees

\begin{tabular}{llll}
\hline Topic & $\begin{array}{l}\text { Mean Likert score } \\
\text { first-time attendees }\end{array}$ & $\begin{array}{l}\text { Mean Likert score } \\
\text { returning attendees }\end{array}$ & $\begin{array}{l}\text { P-value } \\
\text { Confident about who to screen for CHB }\end{array}$ \\
Confident about managing CHB as a notifiable disease & 3.8 & 4.1 & 0.37 \\
Confident about who to vaccinate & 3.9 & 4.2 & 0.32 \\
Confident about who to refer & 4.0 & 4.3 & 0.07 \\
\hline
\end{tabular}

Notes: Likert scale: I not at all confident, 5 very confident.

Abbreviations: GP, general practitioner; $\mathrm{HBV}$, hepatitis $\mathrm{B}$ virus; $\mathrm{CHB}$, chronic hepatitis $\mathrm{B}$. 
(with participants more likely to be interested in $\mathrm{HBV}$ management). The present findings may thus represent a "best case scenario."

The limitations to our study include the fact that despite very high survey response rates (exceeding 95\%) amongst GPs participating in the CME activities, we only reached an estimated $25 \%$ of the total GP workforce in the relevant division of general practice. This raises questions about the representativeness of our findings. The close correlation of our findings with those of US surveys using the same survey instrument would suggest that the sample is representative of the hepatitis B knowledge at the primary care level. ${ }^{16,17}$ Secondly, we cannot assume that improved knowledge of screening and management would necessarily translate into changed hepatitis B testing behavior.

The substantial knowledge gaps about the diagnosis and management of hepatitis B, even amongst medical practitioners originating from countries of high disease prevalence, remain significant barriers to reducing hepatitis B-related burden of disease in high-risk populations, particularly as our findings are corroborated by other Australian quantitative and qualitative surveys, ${ }^{18,19,23}$ as well as by research conducted in the United States and Europe. ${ }^{5,11,24}$ A more concerted action on the part of medical educators and policymakers is needed to address the many missed opportunities to screen for CHB, vaccinate those susceptible, and prevent disease complications. ${ }^{25}$ Since hepatitis B treatment has changed radically in the last two decades (ie, during the time period most of today's practicing GPs were already in medical practice), more opportunities to learn about the modern management of $\mathrm{CHB}$ infection are acutely needed. While there is overall agreement that primary care practitioners need to refresh their hepatitis B knowledge, the evidence is mixed with regards to the most effective forms of CME that can achieve this goal. Similar to Guirgis et al, ${ }^{23}$ we found that Australian GPs prefer large group CME activities to meet their educational needs in hepatitis $\mathrm{B}$, although the complexity of CHB diagnosis and management would suggest that different types of education may be more suitable to this task. ${ }^{26}$ A Cochrane Collaboration review of the effects of continuing education meetings and workshops on professional practice and health care outcomes found their effect on professional practice was small and the effect on patient outcomes even smaller, particularly when targeting behaviors requiring complex judgments or skills. ${ }^{26}$
The role played by online education remains disputed; sustained gains in knowledge have been documented, ${ }^{27}$ but not consistently. ${ }^{28}$ While today's doctors may not yet be ready to embrace web-based learning, ${ }^{29}$ such scenarios may become more popular in the future, provided that benefits outweigh their shortcomings. ${ }^{30,31}$ Combining cycles of web-based teaching with spaced educational emails inviting participant response and providing immediate feedback (as promoted by interactive spaced education), has been shown to improve knowledge retention among medical practitioners, particularly when taught skills and knowledge are infrequently used (as may be the case with hepatitis B diagnosis and management). ${ }^{32,33}$ Very frequent educational emails may, however, further aggravate the chronic time shortages experienced by primary care providers, ${ }^{34}$ who are expected to provide approximately 15 other preventive care interventions during consultations. ${ }^{35}$

A systematic review of the literature on the effectiveness of CME by the American College of Chest Physicians recommended the use of multimedia CME interventions, multiple instructional techniques, and multiple exposures to the CME content. ${ }^{36}$ Replacing a "one size fits all" CME model with a menu of educational activities with flexible modes of delivery and suitable practice support tools may better support primary care providers wishing to remain up to date with the ever-changing face of hepatitis B management.

\section{Conclusion}

In an area of high hepatitis B prevalence in Sydney, Australia, potential hepatitis B disease champions are mostly experienced, bilingual GPs of Asian descent. The very high level of racial and language concordance may translate into better patient-doctor communication and better overall outcomes, ${ }^{37-39}$ provided that ethnic GPs are provided with a range of opportunities to regularly update their knowledge of hepatitis B diagnosis and its management. Although traditional lecturestyle CME education was preferred by most participants, other avenues of CME are required for increasing knowledge retention and to ensure optimized disease outcomes.

\section{Acknowledgments}

This work was funded by Cancer Council New South Wales. Professor Jacob George is supported by the Cancer Council New South Wales, the Robert W Storr bequest to the Sydney Medical Foundation, and by grants from the National Health and Medical Research Council. We would like to thank Steven Tipper and Vidyadhar Putha for their contribution to data collection. 


\section{Disclosure}

The authors report no conflicts of interest in this work.

\section{References}

1. Custer B, Sullivan SD, Hazlet TK, Iloeje U, Veenstra DL, Kowdley KV. Global epidemiology of hepatitis B virus. J Clin Gastroenterol. 2004;38(10 Suppl 3):S158-S168.

2. Lavanchy D. Hepatitis B virus epidemiology, disease burden, treatment, and current and emerging prevention and control measures. J Viral Hepat. 2004;11(2):97-107.

3. Lavanchy D. Chronic viral hepatitis as a public health issue in the world. Best Pract Res Clin Gastroenterol. 2008;22(6):991-1008.

4. World Health Organization. Prevention and Control of Viral Hepatitis Infection: Framework for Global Action. Geneva: World Health Organization; 2012. Available from: http://www.who.int/csr/disease/ hepatitis/GHP_framework.pdf. Accessed January 9, 2013.

5. Rhode Public Policy. Bridging the Gap Between Viral Hepatitis and Liver Cancer. Policy Recommendations of the European Expert Group for Better Control of Liver Cancer by Optimally Managing Viral Hepatitis. Rhode Public Policy; 2012. Available from: http://ashm. org.au/images/hbv/eu\%20policy\%20recommendations\%20bridgingthe-gap_290312.pdf. Accessed January 9, 2013.

6. McBride G. Hepatitis B virus-induced liver cancer in Asian Americans: a preventable disease. J Natl Cancer Inst. 2008;100(8):528-529.

7. Ferrante JM, Winston DG, Chen PH, de la Torre AN. Family physicians' knowledge and screening of chronic hepatitis and liver cancer. Fam Med. 2008;40(5):345-351.

8. Sorrell MF, Belongia EA, Costa J, et al. National Institutes of Health Consensus Development Conference Statement: management of hepatitis B. Ann Intern Med. 2009;150(2):104-110.

9. Weinbaum CM, Williams I, Mast EE, et al; for Centers for Disease Control and Prevention (CDC). Recommendations for identification and public health management of persons with chronic hepatitis B virus infection. MMWR Recomm Rep. 2008;57(RR-8):1-20.

10. Gastroenterological Society of Australia and Digestive Health Foundation. Australian and New Zealand chronic hepatitis B (CHB) recommendations. Clinical update [webpage on the Internet]. Victoria, Australia: The Digestive Health Foundation; 2010. Available from: http://www.gesa.org.au/files/editor_upload/File/Professional/CHB.pdf. Accessed January 9, 2013.

11. Colvin HM, Mitchell AE, editors; for Committee on the Prevention and Control of Viral Hepatitis Infections, Institute of Medicine. Hepatitis and Liver Cancer: A National Strategy for Prevention and Control of Hepatitis $B$ and $C$. Washington, DC: The National Academies Press; 2010.

12. Butler JRG, Korda RJ, Watson KJR, Watson DAR. The Impact of Chronic Hepatitis B in Australia: Projecting Mortality, Morbidity and Economic Impact. ACERH Research Report Number 7. Canberra: Australian Centre for Economic Research on Health (ACERH), the Australian National University; 2009. Available from: http://www.acerh. edu.au/publications/ACERH_RR7.pdf. Accessed January 9, 2013.

13. Robotin MC, Kansil MQ, George J, Howard K, et al. Using a populationbased approach to prevent hepatocellular cancer in New South Wales, Australia: effects on health services utilisation. BMC Health Serv Res. 2010;10(1):215.

14. Dore G, Wallace J, Locarnini S, Desmond P, Gane E, Crawford D. Hepatitis B in Australia: Responding to a Diverse Epidemic. Sydney: Advancing the Clinical Treatment of Chronic Hepatitis B Virus (ACTHBV); 2006. Available from: http://alliance.hepatitis.org.au/uploads/ ACT_HBV.pdf. Accessed January 9, 2013.

15. Tipper S, Penman A. The NSW HBV and liver cancer pilot program: an update on the 'B Positive' Project. Cancer Forum. 2009; 33(2):129-133.

16. Dulay M, Zola J, Hwang J, Baron A, Lai C. Are primary care clinicians knowledgeable about screening for chronic hepatitis B infection? J Gen Intern Med. 2007;22(Suppl 1):747-753.
17. Lai CJ, Nguyen TT, Hwang J, Stewart SL, Kwan A, McPhee SJ. Provider knowledge and practice regarding hepatitis B screening in Chinesespeaking patients. J Cancer Educ. 2007;22(1):37-41.

18. Wallace J, Hajarizadeh B, Richmond J, McNally S. Investigating General Practice and Hepatitis B. Melbourne: Australian Research Centre in Sex, Health and Society, La Trobe University; 2012. Available from: http://www.latrobe.edu.au/arcshs/downloads/arcshs-researchpublications/General-Practice-and-Hepatitis-B-Final-Report.pdf. Accessed January 9, 2013.

19. Wallace J, McNally S, Richmond J. National Hepatitis B Needs Assessment. Melbourne: Australian Research Centre in Sex, Health and Society, La Trobe University; 2007. Available from: http:// cevhap.org/documents/national_hep_b_needs_assesmt.pdf. Accessed January 9, 2013.

20. Matthews G, Robotin M, editors. B Positive - All You Wanted to Know about Hepatitis B: A Guide for Primary Care Providers. Sydney: Australasian Society for HIV Medicine; 2008.

21. Sam JJ, Heathcote EJ, Wong DKH, Wooster DL, Shah H. Hepatitis B learning needs assessment of family medicine trainees in Canada: results of a nationwide survey. Can J Gastroenterol. 2011;25(3):127-134.

22. Australasian Society for HIV Medicine (ASHM). NSW Medicare locals planning project [homepage on the Internet]. Sydney: ASHM; 2012. Available from: http://www.ashm.org.au/default2.asp?active_page_ id=510. Accessed January 9, 2013.

23. Guirgis M, Yan K, Bu YM, Zekri AR. General practitioners' knowledge and management of viral hepatitis in the migrant population. Intern Med J. 2011;42(5):497-504.

24. Ulmer T, Krahmer H. Hepatitis B. Revealing a silent killer. Brussels: European Parliament workshop report; 2006. Available from: http:// onlinelibrary.wiley.com/doi/10.1111/j.1365-2893.2011.01499.x/full. Accessed January 9, 2013.

25. Williams S, Vally H, Fielding J, Cowie B. Hepatitis B prevention in Victoria, Australia: the potential to protect. Euro Surveill. 2011;16(22): 19879.

26. Forsetlund L, Bjørndal A, Rashidian A, et al. Continuing education meetings and workshops: effects on professional practice and health care outcomes. Cochrane Database Syst Rev. 2009;2:CD003030.

27. Fordis M, King JE, Ballantyne CM, et al. Comparison of the instructional efficacy of Internet-based CME with live interactive CME workshops: a randomized controlled trial. JAMA. 2005;294(9):1043-1051.

28. Butzlaff M, Vollmar HC, Floer B, Koneczny N, Isfort J, Lange S. Learning with computerized guidelines in general practice?: A randomized controlled trial. Fam Pract. 2004;21(2):183-188.

29. Vollmar HC, Rieger MA, Butzlaff ME, Ostermann T. General Practitioners' preferences and use of educational media: a German perspective. BMC Health Serv Res. 2009;9:31.

30. Cook DA. Where are we with Web-based learning in medical education? Med Teach. 2006;28(7):594-598.

31. Ruf D, Kriston L, Berner M, Härter M. General practitioners and online continuing medical education - which factors influence its use? Ger Med Sci. 2009;7:Doc08.

32. Kerfoot BP, Baker HE, Koch MO, Connelly D, Joseph DB, Ritchey ML. Randomized, controlled trial of spaced education to urology residents in the United States and Canada. J Urol. 2007;177(4):1481-1487.

33. Kerfoot BP, DeWolf WC, Masser BA, Church PA, Federman DD. Spaced education improves the retention of clinical knowledge by medical students: a randomised controlled trial. Med Educ. 2007;41(1):23-31.

34. Kerfoot BP, Brotschi E. Online spaced education to teach urology to medical students: a multi-institutional randomized trial. Am J Surg. 2009;197(1):89-95.

35. Institute of Medicine. Implementing Colorectal Cancer Screening: Workshop Summary. Washington, DC: The National Academies Press; 2008.

36. Moores LK, Dellert E, Baumann MH, Rosen MJ; for American College of Chest Physicians Health and Science Policy Committee. Executive summary: effectiveness of continuing medical education: American College of Chest Physicians Evidence-Based Educational Guidelines. Chest. 2009;135(Suppl 3):1S-4S. 
37. Cooper-Patrick L, Gallo JJ, Gonzales JJ, et al. Race, gender, and partnership in the patient-physician relationship. JAMA. 1999; 282(6):583-589.

38. Laveist TA, Nuru-Jeter A. Is doctor-patient race concordance associated with greater satisfaction with care? J Health Soc Behav. 2002;43(3):296-306.
39. Manson A. Language concordance as a determinant of patient compliance and emergency room use in patients with asthma. Med Care. 1988;26(12):1119-1128.

\section{Publish your work in this journal}

The International Journal of General Medicine is an international, peer-reviewed open-access journal that focuses on general and internal medicine, pathogenesis, epidemiology, diagnosis, monitoring and treatment protocols. The journal is characterized by the rapid reporting of reviews, original research and clinical studies across all disease areas.
A key focus is the elucidation of disease processes and management protocols resulting in improved outcomes for the patient.The manuscript management system is completely online and includes a very quick and fair peer-review system. Visit http://www.dovepress.com/ testimonials.php to read real quotes from published authors.

Submit your manuscript here: http://www.dovepress.com/international-journal-of-general-medicine-journal 